\title{
POR UNA ANTROPOFAGIA CONTRAPUNTEADA: OSWALD TRANSCULTURADO
}

Maximiliano Linares es Profesor Auxiliar en la cátedra de Literatura Iberoamericana II de la Universidad Nacional de Rosario, Argentina, y se desempeña desde el año 2007 como becario doctoral del Consejo Nacional de Investigaciones Científicas y Técnicas (Conicet), Argentina.

E-mail: maximilianolinares@hotmail.com

\begin{abstract}
Resumen
Desde el replanteo de los espacios conceptuales de la crítica literaria latinoamericana, proponemos abordar puntos plenos de contacto entre la lengua/literatura/crítica hispanoamericana y brasilera. Percibir, intentar y sostener se configura, entonces, como el movimiento primario que llevaremos a cabo en este trabajo a través del análisis del Manifesto Antropófago escrito por Oswald de Andrade en 1928. Esta operación tamizada por los núcleos de pensamiento de y sobre la vertiente antropofágica (Mendonça Teles, 1972; Nunes, 1979) y los de transculturación (Ortiz, 1940; Rama, 1974) parece confluir, creemos, en un espacio potenciador de interpretación de los discursos: el entre lugar de la literatura latinoamericana (Santiago, 1971).
\end{abstract}

\begin{abstract}
Resumo
A partir da reformulação dos espaços conceituais da crítica literária latino-americana, propomos abordar vários pontos de contatos entre língua/literatura/crítica hispano-americana e brasileira. Perceber, tentar e sustentar configura-se, desta maneira, como movimento primário que levaremos a cabo neste trabalho por meio da análise do Manifesto Antropófago escrito por Oswald de Andrade, em 1928. Esta operação observada pelos núcleos do pensamento de e sobre a vertente antropofágica (Teles, 1972; Nunes, 1979) e pelos da transculturação (Ortiz, 1940; Rama, 1974) parece confluir, acreditamos, para um espaço potencializador da interpretação dos discursos: o entre lugar da literatura latino-americana (Santiago, 1971).
\end{abstract}

Percibir la escritura de manifiestos - programas ideológicos, muestrarios de preferencias y desavenencias estético-políticas sostenidos por grupos, núcleos o movimientos de autores- en su intrincada y original dimensión contextual significa emprender un esfuerzo y desafío de lectura de una dificultad tan cierta como necesaria.

Intentar una comprensión de fuerte matriz dialógica para dar cuenta de las vicisitudes socioculturales propias de un espacio y un tiempo sometidos por los períodos y recortes establecidos por el anquilosado esquema centro/periferia implica abordar desdoblamientos y revalorizaciones múltiples de los objetos de estudio.

Sostener una lectura superadora de barreras, diferencias y fronteras naturalizadas por desatención y/o desinterés crítico conlleva, indefectiblemente, un agotador afán por evitar el riesgo del reduccionismo conceptual y la simplificación de las series histórico-literarias.

Percibir, intentar y sostener se configura, entonces, como el movimiento primario que llevaremos a cabo en este trabajo a través del análisis del Manifesto Antropófago escrito por Oswald de Andrade en 1928. Esta operación tamizada por los núcleos de pensamiento de y sobre la vertiente antropofágica (Mendonça Teles, 1972; Nunes, 1979) y los de transculturación (Ortiz, 1940; Rama, 1974) parece confluir, creemos, en un espacio potenciador de interpretación de los discursos: el entre lugar de la literatura latinoamericana (Santiago, 1971).

\section{Serás lo que debas ser pero serás modernista}


El doble e indiscernible carácter con que Lafetá (1974) describe los “pressupostos básicos” del Modernismo brasilero, es decir, su dual componente estético/ideológico, nos sirve para comprender al mismo tiempo otro de los atributos inherentes a este movimiento: su capacidad transformadora.

\begin{abstract}
Nesse ponto encontramos, aliás, uma curiosa convergência entre projeto estético e ideológico: assumindo a modernidade procedimentos expressionais o Modernismo rompeu a linguagem bacharelesca, artificial e idealizante que espelhava, na literatura passadista de 1890-1920, a consciência ideológica da oligarquia rural instalada no poder (...) acrescentando-lhe a força ampliadora e libertadora do folclore e da literatura popular (...) rompendo o bloqueio imposto pela ideologia oficial.
\end{abstract}

(Lafetá, 1974, p.13)

Semejante pulsión liberadora no puede menos que generar no sólo una sino múltiples, y sobre todo diversas, expresiones que configuran una especie de mapeamento articulado de la impronta Moderna/Modernista en el Brasil. ${ }^{1}$

Será el erudito Mendonça Teles (1992) quien con el paso de los años -indispensable distancia para el trazado de una geografía que se reclama espacio/temporal- y luego de sucesivos y siempre perfeccionados intentos - "Nota para a $11^{a}$ ediçao"- ofrezca acaso el más completo esquema de fuerzas en tensión representativas de la inconmensurabilidad territorial brasilera:

\begin{abstract}
Visto em relação com a extensão do território nacional, o modernismo pode ser melhor compreendido através de seus pontos cardeais: um Norte, onde estão as suas fontes nas vanguardas européias; um Sul, ou seja, a sua luta para transformar os valores importados em elementos da cultura brasileira; um Leste, que pode ser lido como o ponto de partida do movimento que se foi ampliando e, em épocas diferentes, chegando a todas as partes do Brasil; e finalmente um Oeste para designar a pluralidade de transformações que, em cada região, foram assinalando e alargando as possibilidades de expressão abertas pelos novos temas, pelas novas técnicas e pelo novo sentido estético da linguagem literária.

(Mendonça Teles, 1992, p. II)
\end{abstract}

A los efectos de lograr una muestra acabada de una de las principales cualidades anotadas por Lafetá -léase capacidad transformadora- atravesada por el eje topográfico de Mendonça Teles -léase un Sur provisto también de las ventajas del reciclaje ${ }^{2}$-, recortamos del corpus básico del Modernismo para su consecuente análisis el Manifesto Antropófago escrito por Oswald de Andrade.

Seriado luego de la inaugural conferencia A emoção estética na arte moderna de Graça Aranha en la "Semana de Arte Moderna" en el Teatro Municipal de Sao Paulo el 13 de febrero de 1922 y del Manifesto da poesia Pau- Brasil del propio Oswald publicado en el Correio da manhá el 18 de marzo de 1924, entre muchos otros textos modernistas, el Manifesto Antropófago se dio a conocer en el primer número de la Revista de antropofagia el $1^{\circ}$ de mayo de 1928, también, en São Paulo.

Ya desde su estilo determinista, contestatario y pretencioso, como cualquier manifiesto que se precie de tal, el texto de Oswald de Andrade ${ }^{3}$ estructura a partir del componente declamativo con que abre la mayoría de sus sintagmas un doble movimiento escriturario, el vaivén destructivo/ propositivo. Veamos. 
Además de copar de manera holgada la tríada indispensable para ser considerada escritura manifiesta esto es, un lenguaje crítico metalingüístico, de fuerte intencionalidad poética y renovado a partir de sus formas (Mendonça Teles, 10)- la pluma de Oswald traza con la condensación del impulso vanguardista europeo en su más rico abanico:

E é precisamente nessa redução que se opera a grande contribuição poética das vanguardas européias, porquanto destruição e construção se apresentam, afinal, como as duas faces de uma mesma realidade: a expressão ordenada ou caótica do universo, seja ele o mundo exterior ou a dimensão psicológica da vida interior. (Mendonça Teles, 1992, p. 29, destacado nuestro.)

En el mismo sentido Nunes (1979) concuerda citando a Martins (1968) para refrendar tres flujos principales en las receptivas costas modernistas: el Futurismo, el Dadaísmo y el Surrealismo, corrientes todas que complementan el binomio destructivo/ propositivo. También advierte, sagazmente:

Numa visão global da vanguarda de 22, pode-se dizer que o grau de receptividade e de resposta a esses estímulos e mensagens esteve condicionado aos diferentes momentos da dialética interna do Modernismo, segundo a ordem de seus problemas estéticos, sociais e políticos. O mais tenso de tais momentos, no qual as relações com as vanguardas européias se tornaram complexas, foi o antropofagismo.

(Nunes, 1979, p. 9, primer y segundo destacado nuestro, tercero del autor ${ }^{4}$ )

La complejidad denotada en las anotaciones de los estudiosos del Modernismo dan cuenta de una dialéctica de impulsos generada conscientemente en el interior/exterior ${ }^{5}$ del Manifesto Antropófago. Compuesto por cincuenta y dos fragmentos o parágrafos cortos - excepto uno, precisamente el que confirma la regla- y concisos, repleto de oraciones unimembres ordenadas cuasi telegráficamente y encabalgadas por una fonética plagada de voces indígenas, el texto fluctúa entre lo que se exige y lo que ya se posee, entre lo que se demanda y lo que se representa, entre lo que se execra y lo que se vanagloria. Por una parte, contamos doce de esos parágrafos iniciados por el vocablo Contra, otros diez encabezados por adverbios privativos Já/ Só/ Ùnica/ Mas/ Nunca seguidos, a veces, por la descalificadora e iterada pregunta Que temos nós com isso?; por otra, al menos seis proposiciones aseverativas desde Estamos/ ̇̀/ Somos/ Queremos y alrededor de doce construcciones descriptivas resaltando positivamente características pro-antropofágicas.

En esta disputa se delinea una doble -al menos- valía, una ingesta pantagruélica que acapara aún negándolos- todos y cada uno de los platos del menú occidental junto al diverso cardapio localista ${ }^{6}$ y una digestión de voluntad totalizadora ${ }^{7}$. Ingerir es paso previo y necesario para digerir: conjugar lo extraño al organismo con los fluidos, membranas, tejidos y gases que lo componen originalmente. Como resultado:

Oswald concebe essa consciência à maneira de um principio ativo de nossa vida intelectual, que deveria vigorar tanto no aproveitamento literário dos aspectos 'bárbaros'da cultura brasileira, quanto na absorção poética dos aspectos ultracivilizados do mundo técnico-industrial. É no Manifesto Antropófago que se percebe porém que o princípio da assimilação, teoricamente formulado, se integrou, tanto quanto o primitivismo, á dialética do movimento modernista.

(Nunes, 1979, p. 29, destacado nuestro)

Absorción y asimilación se convierten en restituibles a partir del entramado de las series de lo Moderno -previsión, orden, razón organizadora, aplicación del impulso progresivo- y lo Primitivo ${ }^{8}-$ 
desafuero, inocencia, pureza, potencia- y de su presencia en el Manifesto mismo: "Só me interessa o que nao é meu. Lei do homem. Lei do antropófago.” (353); “Absorção de inimigo sacro. Para transformá-lo em totem." (359); o, claramente, en "O que se dá não é uma sublimação do instinto sexual. É a escala termométrica do instinto antropofágico." (359)

Finalmente, el tercer parágrafo del Manifesto, magistralmente, alcanza la unidad de los diferentes órdenes sintetizando la proteína base que sostendrá al Antropófago en su renovada existencia, quien se pregunta, precisamente, por esta última: "Tupy, or not Tupy that is the question." (353)

\title{
De narradores, glotones y humores corrosivos
}

\author{
“...el choteo, esa capacidad de no tomar las cosas en \\ serio, de tirarlo todo a relajo, que es identitario de los \\ pueblos caribeños y tal vez habla de salvación ante los \\ peligros de la homogeneización cultural." \\ Félix Valdés García (2004)
}

La risa y la burla como dialogización rabelesiana que permite y empuja a la inversión de los roles predeterminados en una especie de perpetuo Carnaval que fagocita cualquier elemento, cualquier sabor, todas y cada una de las texturas.

Los buches repletos, el estómago henchido, los intestinos ya atorados mientras la pulsión insaciada no acusa recibo, no recula ni para respirar, sólo es cuestión de abrir un poco más las fauces para que ingrese mezclado junto al aire el próximo bocado.

Bernabé (2007) reenvía al pionero contrapunteo cubano de Fernando Ortiz y su, por entonces, novedoso concepto de transculturación ${ }^{10}$ la posterior poética de José Lezama Lima (1969) condensada a partir de la metáfora del "horno transmutativo de la asimilación”. Así establece logradamente una explícita conexión y agrega el plus de la transmigración, de ingerido a asimilado; citamos para apuntalar nuestro derrotero alimenticio:

De ahí que el fogón cubano donde se cocina el festín barroco del Contrapunteo... amalgame ciencia y saber popular, bajos fondos y alta cultura para que la seriedad del académico termine en el tono burlón e irreverente del choteo y del juego de palabras (Bernabé, 2007, p. 101)

En seguida la crítica retoma para aportar la clave conectiva, proveer algunas herramientas imprescindibles y, además, indicar los pasos a seguir para:

Horadar los muros que separan la literatura hispanoamericana de la literatura brasilera, la lengua española de la lengua portuguesa. El puente lo ofrece el pensamiento de la antropofagia de Oswald de Andrade...por un lado, la tensión dialéctica entre elementos contrarios, sobre la que se asientan tanto el contrapunteo cubano como la antropofagia brasilera, funciona a partir de la misma estrategia de asimilación que postula el manejo irreverente y no jerarquizante de los materiales de la alta cultura. Por el otro, la antropofagia forma parte de la extensa tradición literaria latinoamericana que atraviesa las fronteras entre discurso estético y reflexión político-cultural. (Bernabé, 2007, p. 101, destacado nuestro) ${ }^{11}$ 
El entrecruzamiento de esas instancias se verifica tanto en el Manifesto Antropofago como en su antecesor Manifesto Pau-Brasil sin lugar a dudas, pero además es en las novelas del mismo Oswald escritas durante ese período (Memórias sentimentais de João Miramar del '22 y Serafim Ponte Grande publicada en el '33 pero manuscrita entre 1924 y 1928) donde se practica una irreverencia temáticoformal que exuda el espíritu de época, como ya dijimos, un ánimo insaciable en la devoración de lo ajeno combinado con una incontenible ansia de intervención y propagación sobre lo propio.

Ambas as obras (Miramar e Serafim) correm paralelas às poéticas do Pau-Brasil e da Antropofagia no sentido de satirizar o Brasil de aristocracia cafeteira aburguesada nas grandes capitais (e como tal são intencionalmente corrosivos)....

(Bosi, Historia Concisa, citado por Jackson, 1978)

Una vez más la intersección de los discursos se colorea entre las series ya destacadas, discurso estético y reflexión político-cultural, sin dejar de lado el ingrediente cómico-satírico-corrosivo para espantar al burgués. El movimiento intergenérico trazado en nuestro trayecto comenzó en los manifiestos, penduró entre la crítica ensayística y los ensayos de escritores propiamente dichos y aborda ahora las novelas, formato privilegiado para sintomatizar la temperatura cromática de la antedicha coloreada superficie intersectada.

En pos de ello se torna indiscutible conjugar entre nuestros elementos las teorías y los fundamentos de Ángel Rama a partir de su artículo del año 1974 “Los procesos de transculturación en la narrativa latinoamericana"12 donde retoma el concepto de Ortiz en el específico sentido que ya hemos anotado y desarrolla un tránsito detallado de la interacción entre novedosas técnicas estilísticas importadas y temáticas de raigambre regional- localista, configurando así "una respuesta narrativa al conflicto vanguardismo- regionalismo” (Rama, 203):

En el plural panorama aculturante actual, testimonio de la dinámica de las sociedades latinoamericanas
contemporáneas, un capítulo nutrido lo ocupan los conflictos de las sociedades regionales enfrentadas a la
modernización que se incorpora por la vía de puertos y ciudades, que se proclama transmisora del progreso
y que instrumentan las élites rectoras urbanas... Los regionalistas responden a este conflicto: intentarán
evitar la ruptura que se avecina entre los distintos sectores internos que componen la cultura
latinoamericana, debido a la despareja evolución experimentada y a los diversos ingredientes originarios,
cuando ven producirse una aceleración modernizadora ${ }^{13}$." (Rama, 1974, p. 206)

La modernidad se inserta por la vía de ingreso de cualquier novedad significante de la época, accede pomposamente por la puerta grande -las ciudades puerto, los espacios cosmopolitas metropolitanos: Sao Paulo, Rio de Janeiro, Buenos Aires, Lima, Ciudad de México-, perdura en el ambiente y activa resquemores. Estas resistencias son las que Rama selecciona, lee y valoriza. Aún comprendiendo claramente que el impacto modernizador comienza a producirse apenas finalizada la Primera Guerra Mundial, los narradores que integran el seleccionado Rama escriben sus obras-respuestas “capitales” en la década del '50 y '60: Juan Rulfo, Pedro Páramo (1955); José María Arguedas, Los ríos profundos (1958); Joao Guimarães Rosa, Gran Sertão: veredas (1958); y Gabriel García Márquez, Cien años de soledad (1965). ${ }^{14}$ Son cuatro estilos disímiles que, para Rama, contestan cada uno a su modo restituyendo tradiciones locales para mejor “absorver el influjo externo y disolverlo como un simple 
fermento dentro de estructuras artísticas más amplias en las que se siga traduciendo la problemática y los sabores peculiares que venían custodiando.” (207, destacado nuestro)

\title{
Algo más sobre traducción y posicionamiento
}

\author{
"Nada mais original, nada mais intrínseco a si que se \\ alimentar dos outros. É preciso, porém, digeri-los. O \\ leão é feito de carneiro assimilado." \\ Paul Valéry, traducido y citado por Silviano Santiago \\ (1971)
}

La antinomia existente en las dos, mentadas como mayoritarias, maneras de traducir textos -una que se inmola en la literalidad de los signos y otra que se arroja al vacío de la libre interpretación, lo que prueba que traducir siempre es arriesgar- aporta y congrega infinitos posicionamientos respecto a la pertinencia o no del pasaje translinguístico. En una esquina: la copia plana, el simulacro sin relieve, la linealidad de la mimesis como estrategias lisas y llanas de aculturación, así el despojamiento y aniquilamiento de lo propio permitirá ocupar el receptáculo vacío, especie de continente a la espera de su contenido, mera ‘tábula rasa'. En la otra esquina: un modelo no representacional, socavando al referente por contaminación, desarticulando conceptos de unidad y pureza, en una asimilación agresiva disimulada en la falsa obediencia. ${ }^{15}$

[...] uma assimilação inquieta e insubordinada, antropófaga [...] o segundo texto se organiza a partir de uma meditação silenciosa e traiçoeira sobre o primeiro texto [...] em seu movimento de agressão contra o modelo original, fazendo ceder as fundações que o propunham como objeto único e de reprodução impossível. (Santiago, 2000, pp. 20-21, huelga el destacado)

El ensayo de Santiago alimentará desde su génesis la babel de lenguas y discursos enrevesados entre productores centrales y periféricos. "O entre-lugar do discurso latino-americano" fue escrito originalmente en francés bajo el título de "L'entre-lieu du discours latino-américain" -nos informa su autor- para ser leído en una conferencia en la Université de Montréal en 1971. Pero por sugerencia de quien lo invitó debido al carácter "enigmático" del intitulado el conferencista decide reemplazarlo por "Naissance du sauvage, Anthopophagie Culturelle et la Littérature du Nouveau Monde”. Posteriormente, en 1973, se publicará en inglés como "The Latin-American Literature: the Space in-between”, y la versión, al fin, en portugués - "feita pelo autor" aclara, claro, el autor, o sea Santiago- se produce para la publicación del libro Uma literatura nos trópicos en 1977.

Más allá de la evidencia de que en la cláusula en lengua inglesa se reemplace `discurso' por 'Literature' y de que la segunda versión francesa introduzca desde el vamos el condimento antropofágico, lo que nos interesa denotar es el movimiento decidido del intelectual latinoamericano: ante objeciones y desavenencias la estrategia camaleónica del camuflaje, la respuesta muda en aparente doblez para terminar diseminada por las tres lenguas- registros.

También desperdigado, a partir de su potencia inagotable ${ }^{16}$, el Manifesto Antropófago activa desde 1928 las células constitutivas del organismo latinoamericano, cuerpo vivo que no prescinde de las 
lecciones aprendidas -memoria corporal- y se regenera invariablemente en un triple movimiento, "tres focos de acción que se conjugan diversamente: habría pues destrucciones, reafirmaciones y absorciones.” (Rama, 1986, 211)

La palabra final, nobleza obliga, es para Silviano Santiago:

Entre o sacrifício e o jogo, entre a prisão e a transgressão, entre a submissão ao código e a agressão, entre a obediência e a rebelião, entre a assimilação e a expressão - ali, nesse lugar aparentemente vazio, seu templo e seu lugar de clandestinidade, ali, se realiza o ritual antropófago da literatura latino-americana. (Santiago, 2000, p. 26)

\section{Notas}

1 Aquí seguimos el análisis que sugirió y sostuvo el Prof. Cordeiro Gomes durante la cursada del seminario Paradoxos da modernidade e dos modernismos brasileiros: revisões contemporâneas: la evidencia de dar cuenta no de uno, sino de los múltiples y simultáneos modernismos brasileros. En este sentido varios autores y artículos que no son citados en este trabajo nos han servido para pensar estas paradojas, anotamos sus datos completos en el apartado bibliográfico.

${ }^{2}$ Digresión: hallamos muy interesante la noción de pensar un punto geográfico como una cualidad, es decir, lo topográfico que sirve básicamente para indicarnos un rumbo o destino muda a lo toponímico para investir un lugar con un (in)determinada resemantización. En la publicación Transatlántico $\mathrm{N}^{\circ} 3$ del CCPE de Rosario, Argentina, Alan Pauls, quién nació en 1959, dícese "estricto contemporáneo” de Brasilia, inaugurada en 1960; a partir de esto cobra potencia la idea de elucidar un núcleo -1959/60 - ya no sólo como un espacio temporal sino como un espacio físico concreto, esto es, un año/edad igual a una ciudad. Veáse http://www.ccpe.org.ar/transatlantico/03/el-futuroanterior.htm

${ }^{3}$ Para el Manifesto citamos siempre a partir de la edición de Mendonça Teles (1994).

${ }^{4}$ Nunes resalta antropofagismo porque está citando a Haroldo de Campos (2002) en "Uma poética da radicalidade", concepto de Campos sobre la poesía de Oswald de Andrade, entonces, consideramos vital entender a la antropofagia no como una recepción pasiva de un conjunto de técnicas y representaciones del otro sino como una incorporación vigorosa de lo ajeno para reconfigurarse de una manera única y particular como intentamos demostrar.

${ }^{5} \mathrm{Y}$ consideramos este interior/exterior como la marca representativa de la Vanguardia, especie de costura donde puede visualizarse sin esfuerzo la hechura de los procedimientos escriturarios.

${ }^{6}$ El derecho pleno a Occidente que luego conjurará Borges en "El escritor argentino y la tradición” y los valores culinarios nordestinos, entre otros, que dos años antes reclamara Gilberto Freyre en el Manifesto Regionalista. Cabe destacar que el mismo Oswald de Andrade (1972) en una conferencia presentada cincuenta años después de la Semana de Arte Moderna aún sostiene, a su entender, el error de "a sociologia nativa e saudosista do Sr. Gilberto Freyre".

${ }^{7}$ Tan totalizadora como la pulsión digestiva del Modernismo Hispanoamericano, representada en los personajes de José Asunción Silva en su novela De sobremesa (publicada en 1926 -nada menos- después de treinta años de la muerte de su autor) donde los comensales además de comer y beber profusamente permanecen en sus lugares devorando literatura, filosofía y postulados científicos hasta el hartazgo.

8 "Para Oswald de Andrade sobretudo - anota Nunes-, era o primitivismo que nos capacitaria a encontrar nas descobertas e formulações artísticas do estrangeiro aquele misto de ingenuidade e de pureza, de rebeldia instintiva e de elaboração mítica, que formavam o depósito psicológico e ético da cultura brasileira.” (1979, 25-26)

${ }^{9}$ La aclaración corre el riesgo de la tautología pero no pecará de ausente: aquí se reactualiza la cita shakesperiana de "Hamlet" misturada con una palabra indígena, Tupy, que no sólo representa una etnia originaria de Brasil mismo sino también un tronco lingüístico, el tupi-guaraní, que agrupa más de una centena de lenguas aborígenes, aglutinantes y sintéticas, que se extiende por un vasto territorio de América del Sur (Argentina, Bolivia, Brasil, Colombia, Guyana Francesa, Paraguay, Perú y Venezuela).

10 “...transculturación expresa mejor las diferentes fases del proceso transitivo de una cultura a otra, porque este no consiste solamente en adquirir una distinta cultura, que es lo que en rigor indica la voz angloamericana acculturation, sino que el proceso implica también necesariamente la pérdida o desarraigo de una cultura precedente, lo que pudiera

Revista Escrita

Rua Marquês de São Vicente 225 Gávea/RJ CEP 22453-900 Brasil 
decirse una parcial desculturación, y, además, significa la consiguiente creación de nuevos fenómenos culturales que pudieran denominarse de neoculturación. En conjunto, el proceso es una transculturación, y este vocablo comprende todas las fases de su parábola.” (Ortiz, 1991 [1940], 90)

11 El artículo de la Dra. Bernabé fue publicado en el número 5 de Katatay Revista crítica de literatura latinoamericana con el título “Topologías: las fronteras críticas de la literaria (sic) latinoamericana”. En este posible yerro correctivo/ tipográfico o acaso lapsus editorial preferimos leer [preferimos, porque conocemos a la profesora, a los editores y a los correctores de la revista y elegimos no preguntarles] una positiva actitud crítica rayana en la labilidad del neologismo que se condice de lleno con los postulados argumentados en el texto cuando se afirma que "tampoco desaparecen las tensiones desatadas por las diferencias entre el adentro y el afuera porque el contrapunteo jamás abandona el espacio de frontera.”(101)

12 Aquí se vislumbran los nodos principales de pensamiento del crítico uruguayo respecto al tópico de transculturación que luego configurarán el libro Transculturación narrativa en Améria Latina (1982). Citamos a partir de Rama, La novela en América Latina Panoramas 1920-1980 (1986).

${ }^{13}$ Aceleración modernizadora, nomina Rama, y a su tiempo y modo lo harán Sarlo (1988) y Ramos (1989), resultando en una modernidad periférica o desencontrada, respectivamente.

${ }^{14}$ Entre otros también se menciona, pero tangencialmente, a Alejo Carpentier (El reino de este mundo - 1949) a Juan Carlos Onetti (La vida breve - 1950), y a Augusto Roa Bastos (Hijo de hombre - 1960), quienes a estos efectos no condicen plenamente con el filtro temático impuesto por el crítico uruguayo. Restituimos estos autores, porque sostenemos, que junto a los seleccionados por Rama ut supra - con la excepción de García Márquez, por fecha y estilo- representan en su momento la renovación de la novelística latinoamericana. Nótese que proponemos esta 'fuerza' como anterior a la "nueva novela latinoamericana”, esto es, aún precediéndola y posteriormente tomando impulso editorial como "efectos/daños colaterales" del Boom; consideramos mucho más cercana su relación con la Vanguardia Hispanoamericana y el Modernismo Brasilero, una narrativa de una gran condensación poética y características estilísticas (elipsis, montajes, simultaneidad de planos y puntos de vista, etc.) que abrevan en la lectio vanguardi. Por motivos de espacio -cada formato tiene sus propios demonios- continuaremos estas proyecciones en otro trabajo.

${ }^{15}$ Estas nociones, pergeñadas por Silviano Santiago en 1971, nos sorprenden pensando en las categorías de hibridismo de García Canclini (1992) y de hetereogeneidad cultural de Cornejo Polar (1997). Por otra parte, desde la falsa obediencia arribamos a Sor Juana Inés de la Cruz conducidos por “Las tretas del débil” (Ludmer, 1985).

${ }^{16}$ En el doble original carácter antropofágico, ingerir y digerir, media ahora -2009- una tercera característica: la regurgitofagia. Leemos el anuncio callejero de una performance teatral en la ciudad de Rio de Janeiro: "Regurgitofagia. Uma crítica radical e bem- humorada à contemporaneidade. A partir de procedimentos da antropofagia Oswaldiana em novo manifesto e de uma interface tecnológica, as reações sonoras de platéia -risos, aplausos, tosses, etc.- são captadas por microfones e transformadas em descargas elétricas sobre o corpo do a(u)tor." Imaginamos un inicio tímido con algún que otro sonido aislado provocado por los asistentes, una risa generalizada ante los primeros estertores del performer (o performateado en este caso); luego, un silencio nervioso...murmurante... miradas que se cruzan chequeando si lo que ven es, parece o se hace....algunos se levantan para retirarse, pero hacen ruido al incorporarse... se detienen, indecisos...todos (¿todos?) con la risa atragantada y la sensación de que acaban de consumir algo de más, habrá que devolverlo. Veáse http://www.youtube.com/watch?v=rf-VHlkYJeA\&feature=related

\section{REFERENCIAS BIBLIOGRÁFICAS}

ANDRADE, Mario de: “O movimento modernista” en Aspectos da literatura brasileira. São Paulo: Editora Martins, 1942.

ANDRADE, Oswald de. “O Caminho Percorrido” en Ponta de lança en Obras Completas (vol. 5) Rio de Janeiro: Civilização Brasileira, 1972.

BERNABÉ, Mónica. “Topologías: las fronteras críticas de la literaria latinoamericana”, en revista Katatay, año III, № 5, 2007. Veáse también www.katatay.com.ar

BOSI, Alfredo: "Moderno e modernista na literatura brasileira” en Céu, inferno. Ensaios de crítica literária e ideológica. São Paulo: Duas cidades, 2003. 
BÜRGER, Peter. Teoria da vanguarda. Lisboa: Veja, 1993.

CAMPOS, Haroldo de. Oswald de Andrade. Pau- brasil. Sao Paulo: Globo, 2002.

COMPAGNON, Antoine. Os cinco paradoxos da modernidade. Belo Horizonte: Editora UFMG, 1996.

KENNETH, D. Jackson. A prosa vanguardista na Literatura Brasileira: Oswald de Andrade. São Paulo: Editora Perspectiva, 1978.

LAFETÁ, Joao Luiz. “Os pressupostos básicos”en 1930: a crítica e o Modernismo. São Paulo: Duas ciudades, 1974.

LEZAMA LIMA, José. La expresión americana. Montevideo: Arca, 1969.

MENDONÇA TELES, Gilberto. Vanguarda européia e modernismo brasileiro: apresentação dos principais poemas, manifestos, prefácios e conferências vanguardistas, de 1857 a 1972. Petrópolis, RJ: Vozes, 1994 [1972].

NUNES, Benedito: Oswald Canibal. São Paulo: Editora Perspectiva, 1979.

ORTIZ, Fernando. Contrapunteo cubano del tabaco y el azúcar. La Habana: Editorial de Ciencias Sociales, 1991 [1940].

RAMA, Angel. La novela en América Latina. Panorama 1920- 1980. México D. F.: Universidad Veracruzana, 1986.

RAMOS, Julio. Desencuentros de la modernidad en América Latina. México D. F.: Fondo de Cultura Económica, 1989.

SANTIAGO, Silviano. Uma literatura nos trópicos: ensaios sobre dependência cultural. Rio de Janeiro: Rocco, 2000 [1977].

"Fechado para balanço" en Nas malhas da letra. Ensaios. Sao Paulo: Companhia das Letras, 1989.

SARLO SABAJANES, Beatriz. Una modernidad periférica: Buenos Aires 1920 y 1930. Buenos Aires: Nueva Visión, 1988.

VALDÉS GARCÍA, Félix. "El Caribe: integración, identidad y choteo” en http://www.serbi.luz.edu.ve/pdf/upl/v9n27/art_05.pdf

WERNECK DE CASTRO, Moacir: “Cincuenta anos depois” en Jornal do Brasil, $1^{\circ}$ caderno, fecha 2 de mayo de 1992. 